\title{
Point-of-care CD4 testing: Differentiated care for the most vulnerable
}

Elizabeth Spooner ${ }^{1,2}$, Tarylee Reddy ${ }^{3}$, Nobuhle Mchunu ${ }^{3,7}$, Shabashini Reddy ${ }^{4}$, Brodie Daniels ${ }^{2}$, Noluthando Ngomane ${ }^{5}$, Nozipho Luthuli 6 , Photini Kiepiela ${ }^{4}$, Anna Coutsoudis ${ }^{1}$

${ }^{1}$ Department of Paediatrics and Child Health, University of KwaZulu-Natal, Durban, South Africa

${ }^{2}$ South African Medical Research Council, HIV Prevention Research Unit, Durban, South Africa

${ }^{3}$ South African Medical Research Council, Biostatistics Unit, Durban, South Africa

${ }^{4}$ South African Medical Research Council, Durban, South Africa ${ }^{5}$ Occupational Health, Durban, South Africa

${ }^{6}$ eThekwini Health Unit, Durban, South Africa

${ }^{7}$ School of Mathematics, Statistics and Computer Science, University of KwaZulu-Natal, Pietermaritzburg, South Africa

\section{Correspondence to:}

Elizabeth Spooner MBBCh, Diploma in Child Health HIV Prevention Research Unit South African Medical Research Council 491 Peter Mokaba Road

Overport

Durban 4091

South Africa

Elizabeth.Spooner@mrc.ac.za
Background South Africa, with the highest burden of HIV infection globally, has made huge strides in its HIV/ART programme, but AIDS deaths have not decreased proportionally to ART uptake. Advanced HIV disease (CD $4<200$ cells $/ \mathrm{mm}^{3}$ ) persists, and CD4 count testing is being overlooked since universal test-and-treat was implemented. Point-of-care CD4 testing could address this gap and assure differentiated care to these vulnerable patients with low CD4 counts.

Methods A time randomised implementation trial was conducted, enrolling 603 HIV positive non-ART, not pregnant patients at a primary health care clinic in Durban, South Africa. Weeks were randomised to either point-of-care CD4 testing ( $\mathrm{n}=305$ patients) or standard-of-care central laboratory CD4 testing $(n=298$ patients) to assess the proportion initiating ART at 3 months. Cox regression, with robust standard errors adjusting for clustering by week, were used to assess the relationship between treatment initiation and arm.

Results Among the 578 (299 point-of-care and 279 standard-of-care) patients eligible for analysis, there was no significant difference in the number of eligible patients initiating ART within 3 months in the point-of-care (73\%) and the standardof-care $(68 \%)$ groups $(P=0.112)$. The time-to-treat analysis was not significantly different in patients with CD4 counts of 201-500 cells $/ \mathrm{mm}^{3}$ which could have been due to appointment scheduling to cope with the large burden of cases. However, in patients with advanced HIV disease (CD4<200cells $/ \mathrm{mm}^{3}$ ) $65 \%$ more patients started ART earlier in the point-of-care group (HR 1.65 (95\% confidence interval $(C I)=0.99-2.75 ; P=0.052)$ compared to the standard-of-care group.

Conclusions Point-of-care testing decreased time-to-treatment in those with advanced HIV disease. With universal test and treat for HIV, rollout of simple pointof-care CD4 testing would ensure early diagnosis of advanced HIV disease and facilitate differentiated care for these vulnerable patients as per the World Health Organisation 2020 target product profile for point-of-care CD4 testing.

Trial registration ISRCTN14220457.

South Africa bears more than double the HIV burden and antiretroviral treatment (ART) numbers of any other country [1], as well as $10 \%$ of the world's AIDS related deaths [2]. Huge strides have been made in decreasing incidence, increasing life expectancy [3] and decreasing deaths, but the AIDS death rate has not declined as rapidly as expected in the last 6 years, despite the 'test and treat' rollout in 2016 [2] (Figure 1). 


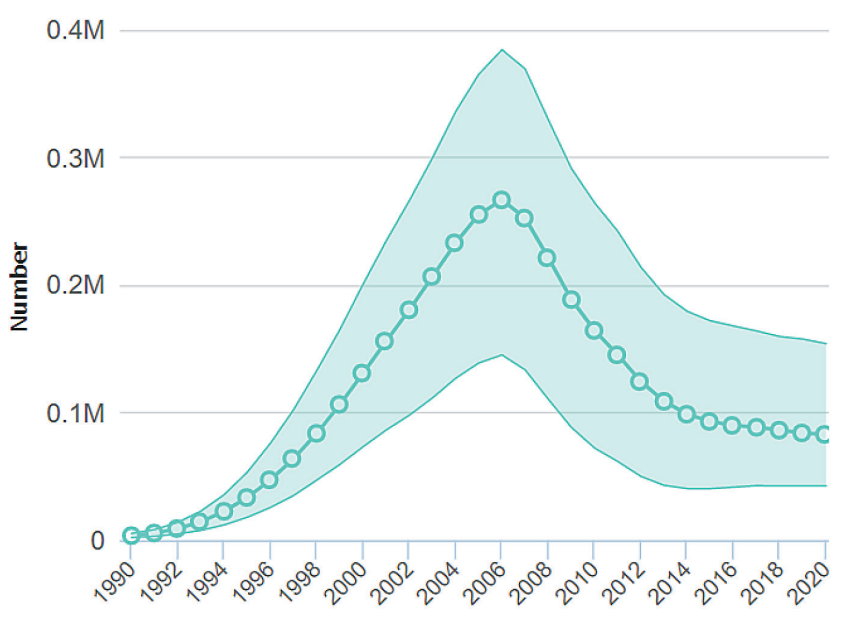

Figure 1. South Africa AIDS-related deaths (all ages) 1990-2020.
There is growing evidence of continued persistent advanced HIV disease (defined as CD $4<200$ cells $/ \mathrm{mm}^{3}$ ) from both late initial presentation which remains relatively unchanged over the last decade [4-7], and increasing disengagement from ART care $[5,8,9]$. This burden of advanced HIV disease accounts for considerable morbidity and mortality and high-cost hospitalizations [10-12] as well as high levels of drug resistance $[13,14]$. CD4 trends are similar from low to high income countries [15] and mortality is underreported [16]. Treatment as prevention of HIV (TasP) also requires that implementation challenges be met to achieve the desired population effect, which has not been seen as consistently as was optimistically anticipated $[17,18]$.

CD4 count testing formed the backbone of historical HIV treatment programmes as a measure of immunocompromise, signifying the need to start ART, as well as for treatment monitoring in many countries. With the emerging evidence of the benefit of ART for all people living with HIV (PLWH), CD4 count thresholds were removed in December 2015 by the World Health Organization (WHO) [19], with universal test and treat (UTT) being adopted in South Africa in 2016. In 2017 the WHO released guidelines for advanced HIV disease, delineating a differentiated care package for those with low CD4 counts [20]. However, CD4 testing has been neglected in the UTT era with baseline CD4 counts missing in up to a third of cases $[15,21,22]$. The proportion of patients with advanced HIV disease in South Africa remained unchanged from 2012-2016 [6], concurring with the plateau in AIDS-related deaths. The importance of baseline and ongoing CD4 monitoring during advanced HIV disease has been emphasized across many settings [23-25].

Point of care (POC) CD4 testing has been shown to be accurate [26,27] (particularly at lower CD4 counts) and cost-effective $[28,29]$, and has been used in many studies (both home and facility-based), that facilitated linkage to care, ART uptake [30-32] and viral suppression [33,34]. It has also been found to be acceptable [35] and requested by health care workers [36].

This study was conducted in a primary health care (PHC) clinic in Durban, South Africa, to evaluate if POC CD4 testing improved ART initiation, time to treatment initiation and linkage to care.

\section{METHODS}

A time-randomized effectiveness-implementation study was conducted at Lancers Road PHC clinic, adjacent to a busy taxi rank in the Durban city-center from April to October 2015. The clinic initiated over $2500 \mathrm{pa}-$ tients on ART in 2015. HIV positive adults, ART naive and not pregnant, requiring CD4 testing were enrolled. Weeks were randomized to either: standard-of-care (SOC) central laboratory CD4 testing sent from the clinic via the Addington Hospital Laboratory to the Prince Mshiyeni Hospital for flow-cytometry CD4 testing; or Alere тM PIMA POC CD4 (now Abbot PIMA ${ }^{\text {TM }}$ CD4) testing at the clinic. SOC weeks were 2; 4; 6-7; 11-14; 17; 20; $22 ; 24 ; 25$ (13 weeks) and POC weeks were 1; 3; 5; 8-10; 15-16; 18-19; 21; 23; 26 (13 weeks). Participants were referred by clinic staff for testing and no participants refused participation. Voluntary written informed consent was obtained from all participants.

\section{Study intervention}

3 PIMA analyzers were available for testing during PIMA randomized weeks and packed away on SOC weeks. Control beads were run each morning on the analyzers and all results were sent to Datapoint daily via the modem supplied by Alere. Study staff received Alere PIMA end user training with certificates. Study questionnaires were completed during the 20-minute PIMA specimen processing time during POC weeks. Participants were given the choice of fingerstick or venous blood draw (EDTA tube) for the POC testing with 148/299 (50\%) choosing fingerstick. Participants known to be ART eligible were advised to have a venous draw to include required baseline bloods tests. All required phlebotomy was performed by the study staff. PIMA results were printed out (on supplied heat printers) and retained for study records. SOC participants were given a return date for 3-7 days to collect their results. Participants were integrated back into the clinic system and given a follow-up study visit appointment after 3 months if eligible for ART and 6 months if not yet eligible. These 
follow-ups were in-person or by telephone call if they did not attend a visit. Text message reminders were sent for follow-up visits if they did not attend. Study questionnaires collecting demographic and background information were administered at baseline and follow-up visits (Appendix S1 and S2 in the Online Supplementary Document). An exploratory objective included following-up the Lancers Road cohort until 5 years on ART from the clinic's electronic ART records (part of the national Tier.net database).

\section{Statistical analysis}

The study employed a cluster randomized design, where each week represents a cluster. Block randomization with block sizes of 4 were used to randomize across clusters. Assuming 60\% of eligible patients in the SOC group initiate ART, sample sizes of 180 in each group (obtained by sampling 9 clusters of 20 subjects in each group) would achieve $80 \%$ power to detect a $15 \%$ improvement (ie, ART Initiation rate of $75 \%$ in the POC group). Block randomization with block sizes of 4 were used to randomize the POC/SOC across clusters. Generalised estimating equations models, with logit link were used to assess the relationship between study arm and starting ART within 90 days, while adjusting for correlation within cluster (randomization week). The probability of initiating treatment was presented graphically using Kaplan-Meier failure curves. Cox regression, with robust standard errors adjusting for clustering by week, were used to assess the relationship between treatment initiation and arm. Interaction effects between arm and CD4 count category were included in the models to conduct subgroup analyses. The Shapiro-Wilk test as well as quantile-quantile (Q-Q) plots and normal probability plots were used to assess normality assumptions of the continuous variables. Normally distributed variables were thus expressed as means with standard deviations, while continuous variables that violated normality assumptions were expressed as medians with interquartile ranges (IQRs). All analysis was conducted using Stata 15 (StataCorp, College Station, TX, USA).

\section{Ethics}

Ethics approval was obtained from the Biomedical Research Ethics Committee of the University of KwaZulu-Natal (BF 480/14) and the eThekwini Research Ethics Committee. Clinical Trial Number: ISRCTN14220457.

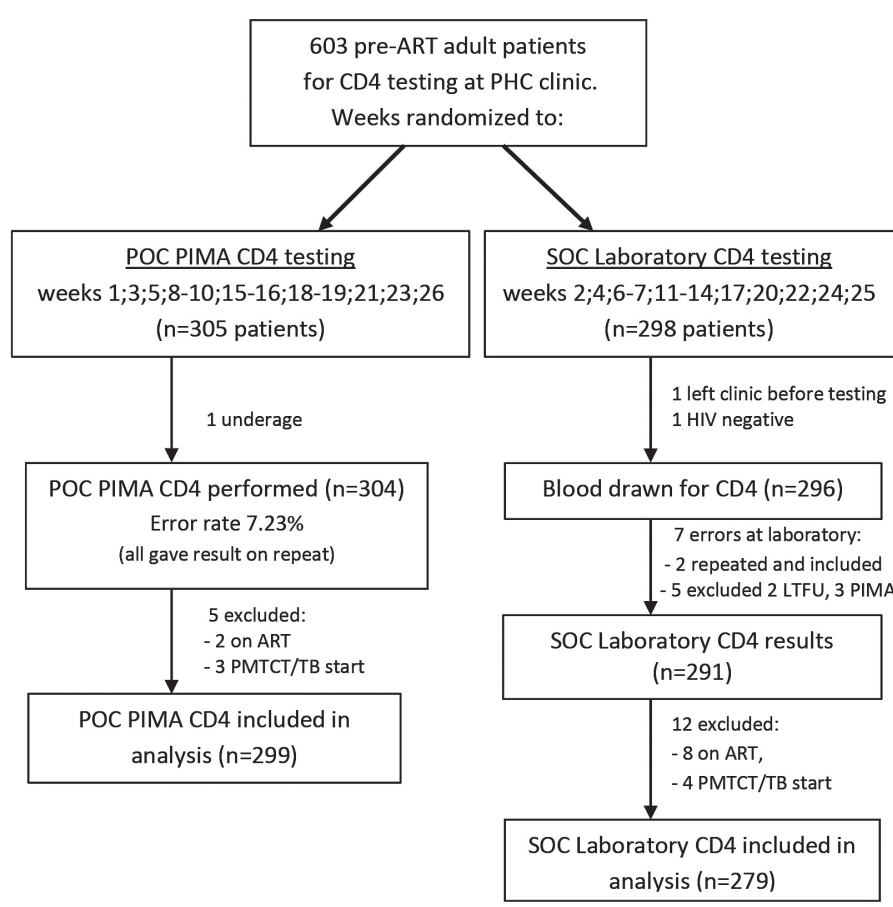

Figure 2. Flow diagram of cohort: HIV positive adults at Lancers Road PHC clinic, Durban (Not on ART; Not pregnant). SOC laboratory CD4 testing - standard-of-care central laboratory testing at the National Health Laboratory Services; POC PIMA CD4 testing - point-of-care PIMA ${ }^{\mathrm{TM}} \mathrm{CD} 4$ testing at the clinic; $\mathrm{PHC}$ - primary health care; LTFU lost to follow up; PMTCT/TB - prevention of mother to child transmission (pregnant) or tuberculosis ART start at any CD4 count

\section{RESULTS}

A flow diagram (Figure 2) details the randomization weeks and exclusions in each group.

\section{Baseline characteristics and history}

There were no notable significant differences between the POC and SOC groups at baseline. Table 1 shows the sociodemographic characteristics with 3 out of 4 patients being female. Almost half (47\%) had not completed high school, a third (35\%) had no form of employment and half (49\%) were receiving state grants.

Table 2 reveals baseline HIV and CD4 characteristics with a third (34\%) of patients testing HIV positive for the first time. In patients with advanced HIV disease $\left(\mathrm{CD} 4 \leq 200\right.$ cells $\left./ \mathrm{mm}^{3}\right), 40 \%$ tested HIV positive for the first time. The majority of those previously diagnosed were in the preceding year (41\%), with almost a quarter knowing their status for more than 5 years. Over a third (36\%) had never had a CD4 test despite knowing their HIV status and of those who had a previous CD4 count, $55 \%$ had been at a different health care facility.

\section{CD4 testing results}

The CD4 results and distribution is seen in Table 3. The cumulative distribution by CD4 category is summarized in Figure 3 with 407/578 (70\%) of patients eligible for 
Table 1. Sociodemographic characteristics

\begin{tabular}{|c|c|c|c|c|}
\hline CHARACTERISTIC* & ALL & POC PIMA CD4 TEST & SOC LABORATORY CD4 TEST & P-VALUE \\
\hline Total $\mathrm{n}=$ & 578 & 299 & 279 & \\
\hline Female & $430(74 \%)$ & $221(74 \%)$ & $209(75 \%)$ & 0.731 \\
\hline Male & $148(26 \%)$ & $78(26 \%)$ & $70(25 \%)$ & \\
\hline Age, median (IQR) & $31(26-37)$ & $32(25-38)$ & $31(26-37)$ & 0.781 \\
\hline Female's age, median (IQR) & $31(25-36)$ & $31(24-36)$ & $31(26-35)$ & \\
\hline Male's age, median (IQR) & $33(29-41)$ & $33(30-40)$ & $34(28-43)$ & \\
\hline \multicolumn{5}{|l|}{ Highest education: } \\
\hline None & $8(1 \%)$ & $3(1 \%)$ & $5(2 \%)$ & 0.960 \\
\hline Less than secondary & $268(46 \%)$ & $139(47 \%)$ & $129(46 \%)$ & \\
\hline Completed secondary & $274(47 \%)$ & $144(48 \%)$ & $130(47 \%)$ & \\
\hline Tertiary & $28(5 \%)$ & $13(4 \%)$ & $15(5 \%)$ & \\
\hline \multicolumn{5}{|l|}{ Employment: } \\
\hline Full time formal & $156(27 \%)$ & $78(26 \%)$ & $78(28 \%)$ & 0.326 \\
\hline Part time/casual/self employed & $221(38 \%)$ & $129(43 \%)$ & $92(33 \%)$ & \\
\hline Unemployed & $201(35 \%)$ & $92(31 \%)$ & $109(39 \%)$ & \\
\hline \multicolumn{5}{|l|}{ Current partner: } \\
\hline Single & $104(18 \%)$ & $54(18 \%)$ & $50(18 \%)$ & \\
\hline Has current partner & $474(82 \%)$ & $245(82 \%)$ & $229(82 \%)$ & 0.962 \\
\hline Live with current partner $(n=469)$ & $121(26 \%)$ & $66(27 \%)$ & $55(24 \%)$ & 0.433 \\
\hline Married $(n=470)$ & $57(12 \%)$ & $29(12 \%)$ & $28(13 \%)$ & 0.664 \\
\hline Current multiple partners $(n=471)$ & $52(11 \%)$ & $23(9 \%)$ & $29(13 \%)$ & 0.272 \\
\hline Partner's HIV status reported $(n=469)$ : & 469 & 241 & 228 & \\
\hline Partner's HIV status unknown & $240(51 \%)$ & $126(52 \%)$ & $114(50 \%)$ & 0.801 \\
\hline Partner's HIV status negative & $54(12 \%)$ & $24(10 \%)$ & $30(13 \%)$ & 0.801 \\
\hline Partner HIV known infected & $175(37 \%)$ & $91(38 \%)$ & $84(37 \%)$ & \\
\hline Partner, if infected on ART & $91(52 \%)$ & $47(52 \%)$ & $44(48 \%)$ & 0.933 \\
\hline Have biological children: & $455(79 \%)$ & $226(76 \%)$ & $229(82 \%)$ & \\
\hline No of biological children & $2(1-3)$ & $2(2-3)$ & $2(1-3)$ & 0.325 \\
\hline Live with any of their children & $148(33 \%)$ & $71(31 \%)$ & $77(34 \%)$ & 0.058 \\
\hline \multicolumn{5}{|l|}{ Dwelling: } \\
\hline Formal & $505(87 \%)$ & $252(84 \%)$ & $253(91 \%)$ & 0.022 \\
\hline Informal & $73(13 \%)$ & $47(16 \%)$ & $26(9 \%)$ & \\
\hline \multicolumn{5}{|l|}{ Income $(\mathrm{n}=576)$ : } \\
\hline Receiving any welfare grants & $284(49 \%)$ & $138(46 \%)$ & $146(52 \%)$ & 0.177 \\
\hline Monthly personal income - median ZAR & $2000-3000$ & $2000-3000$ & $2000-3000$ & \\
\hline US\$ & $157-235$ & $157-235$ & $157-235$ & \\
\hline
\end{tabular}

POC - point-of-care, PIMA - Abbot PIMA ${ }^{\mathrm{TM}} \mathrm{CD} 4$, SOC - standard of care, IQR - interquartile range, ART - antiretroviral therapy, ZAR - South African Rands,

US\$ - United States Dollars

*Denominators in brackets, depending on data available.

Table 2. HIV status and prior CD4 testing

\begin{tabular}{|c|c|c|c|c|}
\hline & TOTAL & POC PIMA CD4 TEST & SOC LABORATORY CD4 TEST & P-VALUe \\
\hline Total n- & 578 & 299 & 279 & \\
\hline \multicolumn{5}{|l|}{ HIV status } \\
\hline First HIV positive test on enrolment day & $194(34 \%)$ & $103(34 \%)$ & $91(33 \%)$ & 0.641 \\
\hline Previously tested HIV positive & $384(66 \%)$ & $196(66 \%)$ & $188(67.4)$ & \\
\hline \multicolumn{5}{|l|}{ Duration of knowing HIV positive status * $\mathrm{n}=381$ : } \\
\hline$<6$ months & $105(28 \%)$ & $63(32 \%)$ & $42(23 \%)$ & 0.204 \\
\hline 6-12 months & $48(13 \%)$ & $26(13 \%)$ & $22(12 \%)$ & \\
\hline$>1-3$ years & $96(25 \%)$ & $41(21 \%)$ & $55(30 \%)$ & \\
\hline$>3-5$ years & $43(11 \%)$ & $20(10 \%)$ & $23(12 \%)$ & \\
\hline$>5$ years & $89(23 \%)$ & $46(24 \%)$ & $43(23 \%)$ & \\
\hline Missing & 3 & 0 & 3 & \\
\hline Months known HIV positive status, median (IQR) & $14(3-44)$ & $12(3-48)$ & $18.5(3-44)$ & 0.347 \\
\hline Disclosed status previously & $334(87 \%)$ & $171(87 \%)$ & $163(87 \%)$ & 0.874 \\
\hline
\end{tabular}


Table 2. continued

\begin{tabular}{|c|c|c|c|c|}
\hline & TOTAL & POC PIMA CD4 TEST & SOC LABORATORY CD4 TEST & P-VALUE \\
\hline \multicolumn{5}{|l|}{ Previous CD4 count: } \\
\hline No previous CD4 despite prior positive HIV test & $138(36 \%)$ & $76(39 \%)$ & $62(33 \%)$ & 0.237 \\
\hline Previous CD4 count taken - one or more & $246(64 \%)$ & $120(61 \%)$ & $126(67 \%)$ & \\
\hline Knew previous CD4 test result (even estimated) & $216(82.4)$ & $111(88.9)$ & $105(76.4)$ & 0.034 \\
\hline Didn't know previous CD4 test result & $30(17.6)$ & $9(11.1)$ & $21(23.6)$ & \\
\hline Previous CD4 at a different health facility $n=241$ & $133(55 \%)$ & $67(56 \%)$ & $66(54 \%)$ & 0.731 \\
\hline Previous CD4 at this facility & $108(45 \%)$ & $52(44 \%)$ & $56(46 \%)$ & \\
\hline
\end{tabular}

POC - point-of-care, PIMA - Abbot PIMA ${ }^{\mathrm{TM}} \mathrm{CD} 4, \mathrm{SOC}$ - standard of care, IQR - interquartile range

*Denominators depending on data available

Table 3. CD4 count results

\begin{tabular}{lcccc} 
CD4 counts & TOTAL N = 578 & POC PIMA N = 299 & SOC LABORATORY N = 279 & P-VALUE \\
Median (IQR) & $357(211-526)$ & $357(225-522)$ & $356(197-530)$ & 0.808 \\
\hline$\leq 50 \mathrm{cell} / \mathrm{mm}^{3}$ & $26(5 \%)$ & $11(4 \%)$ & $15(5 \%)$ & 0.717 \\
\hline $51-100 \mathrm{cell} / \mathrm{mm}^{3}$ & $27(5 \%)$ & $17(6 \%)$ & $10(4 \%)$ & $45(16 \%)$ \\
\hline $101-200 \mathrm{cell} / \mathrm{mm}^{3}$ & $78(13 \%)$ & $33(11 \%)$ & $65(23 \%)$ & $59(21 \%)$ \\
\hline $201-350 \mathrm{cell} / \mathrm{mm}^{3}$ & $150(26 \%)$ & $85(28 \%)$ & $85(30 \%)$ & \\
\hline $351-500 \mathrm{cell} / \mathrm{mm}^{3}$ & $126(22 \%)$ & $67(22 \%)$ & $86(29 \%)$ & \\
\hline$>500 \mathrm{cell} / \mathrm{mm}^{3}$ & $171(30 \%)$ & &
\end{tabular}

$\mathrm{POC}$ - point-of-care, PIMA - Abbot PIMA ${ }^{\mathrm{TM}} \mathrm{CD} 4, \mathrm{SOC}$ - standard of care, IQR - interquartile range

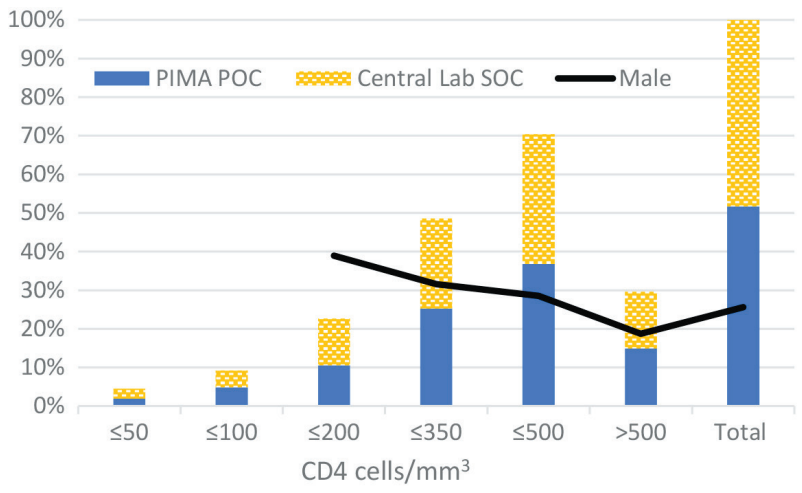

Figure 3. Cumulative CD4 counts for all participants per CD4 category $\mathrm{n}=578$. PIMA POC - Alere ${ }^{\mathrm{TM}}$ PIMA point of care CD4 testing,Central Laboratory SOC - Central Laboratory standard of care CD4 testing; Male - proportion of males within CD4 category
ART (CD4 $\leq 500$ cells/mm $\mathrm{mm}^{3}$ ) while 131/578 (23\%) had advanced HIV disease (CD4 $\leq 200$ cells $\left./ \mathrm{mm}^{3}\right)$. There was no significant difference between the SOC and POC groups. Males had a lower median CD4 count of 256 cells $/ \mathrm{mm}^{3}(\mathrm{IQR}=157-467)$ compared to females' median CD4 383 cells $/ \mathrm{mm}^{3}(\mathrm{IQR}=234-548)$. The overall proportion of males was $26 \%$ but increased in the $\leq 350$ cells $/ \mathrm{mm}^{3}$ category to $32 \%$ and in the $\leq 200$ cells $/ \mathrm{mm}^{3}$ category, with advanced HIV disease, males constituted 39\%.

In the SOC group there were 7 laboratory errors, 2 of which were repeated, 2 were LTFU and 3 had PIMA (as returned in a PIMA week) and were therefore excluded. PIMA testing had an error rate of $7.3 \%$ with all giving a result on repeat testing.

\section{ART initiation and time to treat}

The primary end point analysis revealed that of all the participants eligible for ART ( $\mathrm{n}=406), 73 \%$ in the POC PIMA and 68\% in the SOC Central laboratory group, initiated ART within 3 months/90 days, although this difference did not reach statistical significance. The time to treatment analysis excluded those eligible for ART who were LTFU after enrolment $(\mathrm{n}=39)$ and revealed no significant difference across all patients eligible for ART at 3 months / 90days ( $\mathrm{HR}=1.12,95 \%$ confidence interval $(\mathrm{CI})=0.85-1.48 ; \mathrm{P}=0.41$ ) (Figure 4).

When stratified by CD4 category (Figure 5), a difference between the POC and SOC groups was noted in the $\mathrm{CD} 4<200$ cells $/ \mathrm{mm}^{3}$ category ( $\left.\mathrm{HR}=1.65,95 \% \mathrm{CI}=0.99-2.75 ; P=0.052\right)$; effectively $65 \%$ more patients in the POC group started ART within 90 days. This however denotes only borderline significance due to the small sample number in this group. The supplementary material shows the other CD4 category's Kaplan-Meier curves (Figure S1 in the Online Supplementary Document).

\section{Patient inconvenience}

Figure 6 depicts the types of leave taken as reported by 248/578 (43\%) of patients. An additional 97(17\%) students and learners may have missed school/lectures. A further 80/578 (14\%) mentioned loss of income 


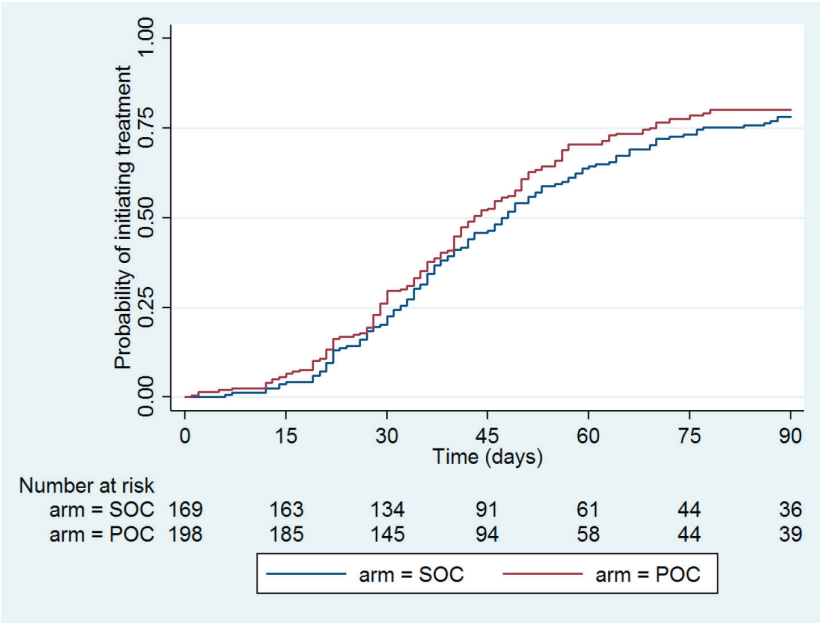

Figure 4. Kaplan-Meier curve of time to treat - OC PIMA vs SOC laboratory, all CD4 counts. SOC - standard-of-care central laboratory CD4 testing, POC - point-of-care PIMA ${ }^{\mathrm{TM}}$ CD4 testing.

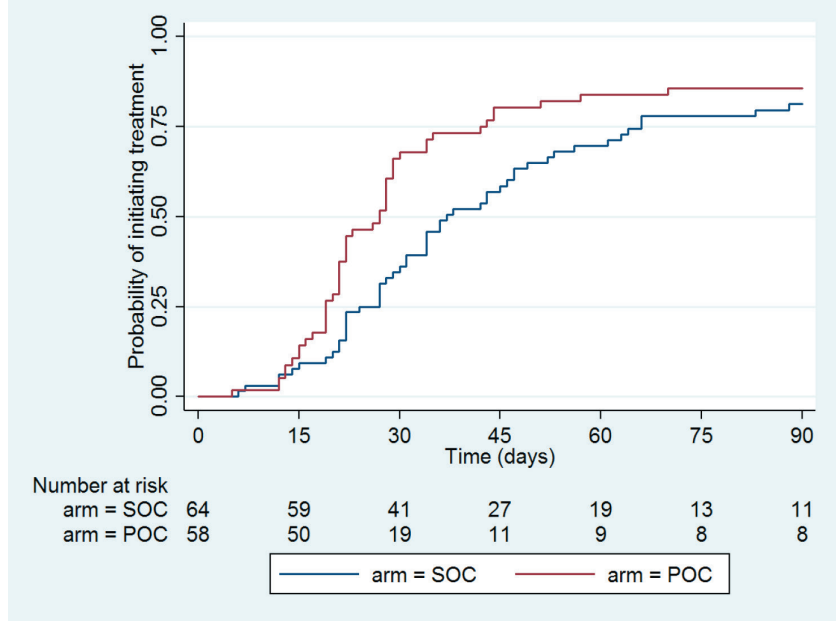

Figure 5. Kaplan-Meier curve of time to treat - POC PIMA vs SOC laboratory, advanced HIV disease (CD4 $\leq 200$ cells $\left./ \mathrm{mm}^{3}\right)$. SOC - standard-of-care laboratory CD4 testing, POC - point-of-care PIMA $^{\mathrm{TM}}$ CD4 testing.

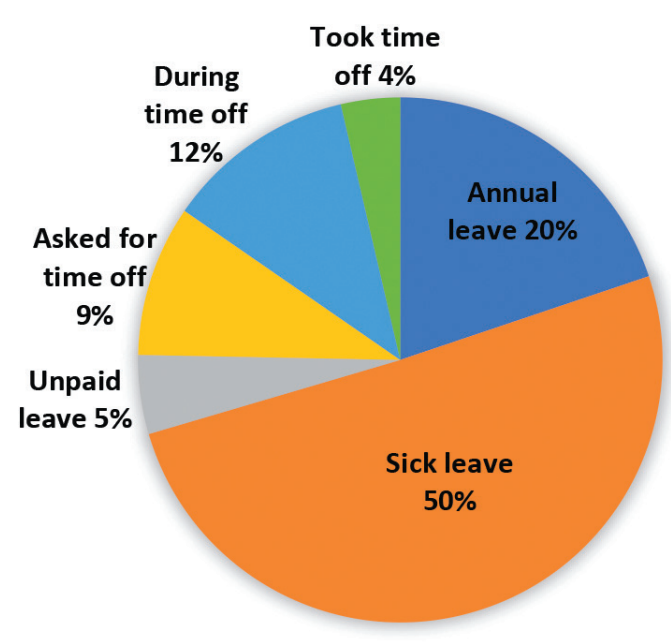

Figure 6. Leave types taken as reported by patients $n=248$.

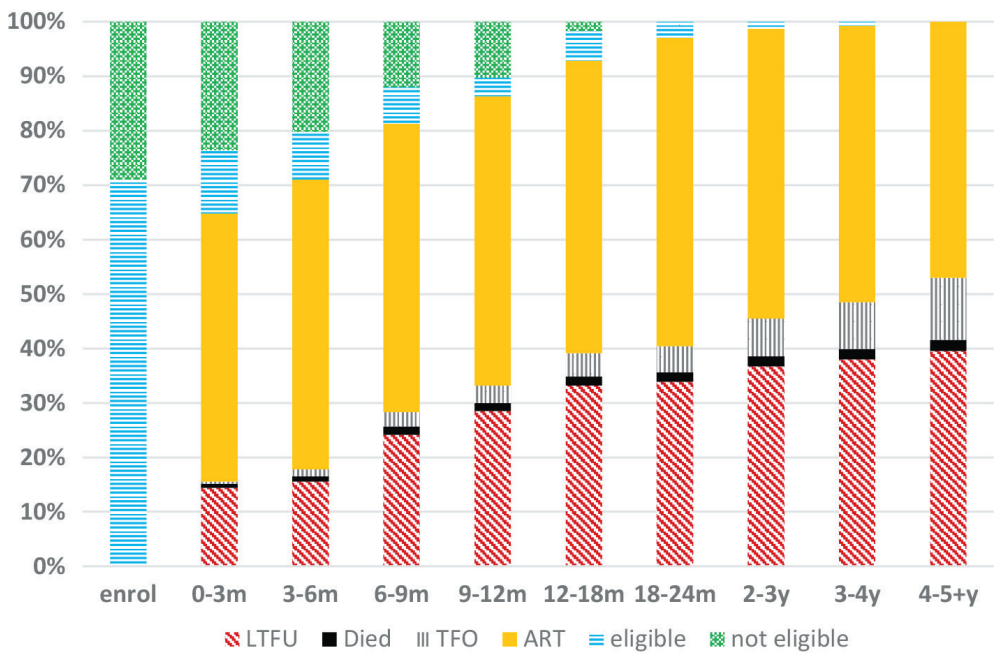

Figure 7. Lancers Road clinic 5-year ART retention $n=534$ (2015-2020). LTFU lost to follow up, TFO - transferred out, ART - on antiretroviral treatment, eligible - CD $4 \leq 500$ cells $/ \mathrm{mm}^{3}$, not eligible - CD $4>500$ cells $/ \mathrm{mm}^{3}$.

for coming to the clinic with a median of ZAR 100-150 (US\$ 8-12) reported. The median transport cost was ZAR14 (US\$1) (IQR=ZAR 10-21 (US\$ 1-2)) per patient for the day for the 375/578 (65\%) who paid for transport, while $31 \%$ walked to the clinic with a median travel time of 30-60 minutes per day for all participants.

\section{Retention in care}

Retention in care did not differ significantly between the PIMA POC and SOC central testing groups. Of the cohort, 63/578(11\%) were lost to follow up (LTFU) directly after their enrolment visit. Another 45/578 (8\%) were found to have linked to care at other clinics upon follow up call: 24/45 (53\%) within eThekweni, 8/45 (17\%) in KwaZulu-Natal province, $7 / 45$ (15\%) in other provinces and 6/45 (13\%) at unknown clinics and GPs. Of the patients who started ART at Lancers Road PHC, 17/410 (4\%) never returned after their first ART initiation visit - and so it is unknown if they truly started treatment.

Figure 7 gives a summary of the Lancers Road cohort over 5 years. UTT was implemented in South Africa at the 12-18-month time point when all patients became eligible for ART. At 5 years, 251/534 (47\%) were in care and $61 / 534(11 \%)$ had transferred out to other facilities. Of the 211/534 (40\%) who were LTFU at 5 
years, 121/211 (57\%) never started ART at Lancers Road PHC, which represented 121/534 (23\%) of the total. Of the 323 patients who initiated ART at Lancers Road PHC, 15 (5\%) re-engaged after being LTFU from ART over the 5 yr period.

\section{DISCUSSION}

This cohort tells the all too familiar story of HIV in Sub-Saharan Africa - of patients in and out of care, vulnerable patients, few men in care, poverty, and a heavily burdened clinic service [37]. Despite this, the cohort describes better ART initiation and linkage than many other services in South Africa which is a commendation to the dedicated staff at the clinic $[6,38,39]$.

Previous CD4 testing had been at a different facility in 55\% of patients presenting for care, $8 \%$ of the cohort linked to care at a different facility after testing, and $11 \%$ had transferred out from ART care by 5 years, highlighting the well documented mobility of patients accessing care $[18,40,41]$.

The introduction of UTT in 2016 caused the ART initiation numbers to increase by a further 30\%, with the patients with CD4>500 cells $/ \mathrm{mm}^{3}$ becoming eligible and placing further strain on the health system.

UNAIDS proposed the 90-90-90 targets: 90\% of PLWH know their status, 90\% of those diagnosed with HIV receive ART and $90 \%$ of those on ART are virally suppressed. While the study was not designed to detect the $5 \%$ difference in time to treat, this difference is clinically meaningful as every patient on ART adds towards reaching the second ' 90 ' target, which is currently at 72\% [2] Previous studies have reported improvements in time to treat and linkage to care [31,42] while others have not [43-45].

The study design allowed a robust, time-randomized implementation method where all study participants were part of the same process, with half randomized to the POC intervention. This ensured that they all received the same time with a health care worker, counselling and information, which has been shown to be an important factor in ART initiation and linkage to care [46,47]. As patients still had to wait for baseline blood results from the central laboratory prior to initiation, same-day ART initiation could not occur in the POC group. Patients with CD4 counts above 200 cells $/ \mathrm{mm}^{3}$ were also given appointments to return for ART initiation 4-6 weeks after eligibility due to high patient numbers, which interfered with the time to treat analysis for the groups - a real-world challenge in implementation studies [48].

Despite this cohort being prior to UTT rollout, it demonstrates that POC CD4 testing benefits those with advanced HIV disease significantly by identifying them and differentiating care for this vulnerable population. This benefit is even more applicable since UTT, where CD4 testing is being neglected and advanced HIV disease and mortality persists [4]. The higher proportion of men (40\%) with advanced disease is not uncommon [38], and these men would likely have higher viral loads, thus transmitting the virus more readily. Engaging those who are continuing to drive the epidemic is a priority [49].

The five-year follow-up data for the cohort at Lancers Road clinic shows $47 \%$ of patients still in care at the clinic, with $11 \%$ having formally transferred to other clinics, and increasing LTFU with time. The deaths are likely underestimated and self-transfers are not able to be tracked beyond the follow-up calls. This is similar to other reports of retention in care at similar time periods $[50,51]$. This continuity of care requires a huge effort for a PHC clinic with 3723 patients in ART care in 2015 (now 8102 patients in ART care by November 2020) (Pers report Sr N Luthuli, Lancers Road Clinic). However, this retention and LTFU make the UNAIDS 90-90-90 targets [52] difficult to reach [53].

CD4 count is the primary method of assessment of advanced HIV disease, as even with a CD4 $<100$ cells $/ \mathrm{mm}^{3}$, half of patients may have asymptomatic disease [54]. Advanced HIV disease was diagnosed in 23\% of the cohort with $40 \%$ of these being diagnosed HIV-infected for the first time at enrolment. Prompt differentiation of care for these patients gives them the best chance of survival and recovery. This targeted management of advanced HIV disease is the WHO strategy to differentiate care to these vulnerable PLWH with the highest morbidity and mortality $[20,55]$. CD4 count is thus still essential for:

1. a baseline assessment for all at ART initiation,

2. continued monitoring for those with advanced HIV disease on prophylaxis regimens,

3. those presenting for ART after disengagement/ treatment interruption,

4. those with unsuppressed viral loads (due to poor adherence or treatment failure),

5. ad hoc CD4 testing for those presenting with symptomatic disease. 
Point-of-care CD4 testing will allow health care workers to identify rapidly those requiring differentiated care for advanced disease, therefore providing the correct care, counselling, and education for this population at highest risk of morbidity, mortality, and ongoing transmission. Other valuable POC tests at this time point are creatinine and haemoglobin, the TBLAM urine test, Cryptococcal Ag test, Hepatitis B Ag test and a POC TB sputum test which would assist with a comprehensive diagnostic picture and ensure the comprehensive package of care is delivered, together with the adapted adherence support and follow-up as per WHO guidelines [20].

POC CD4 testing has been found to be acceptable to staff and patients [35] and requested by nurses [36]. A blood test is only valuable if it leads to better outcomes for the patient. POC testing assists with the same day actioning of a result by the health care team to ensure appropriate care, treatment, counselling, and follow-up for patients. This averts the delays experienced even in first world, highly computerised settings [56], which are a very common experience in our clinics with repeated testing and additional costs and time to the health system and to patients. POC testing can streamline services and allow more time for better care by decreasing the number of visits to the clinic and facilitating a 'one stop shop'. Improving retention requires many more innovative and sensitive strategies to tackle the social, economic factors and unmet needs of PLWH who may cycle in and out of care over time [57-60].

A limitation of this study was that the POC testing was performed by study staff and not by the clinic staff, however other studies have shown feasibility and effectiveness of nurses, or even task shifting to lay health care workers, to perform PIMA testing [61]. The possibility of 'silent transfers' with patients moving to other clinics for care without official transfers when on ART or moving preART to other facilities could not be monitored. The 3-8-month follow-up calls to participants did document some of these "silent transfers". However, this active follow-up of participants could also have been an added encouragement to patients and so increased their linkage to care beyond that of a non-research cohort giving an optimistic report of ART start and retention. Deaths were also likely to have been underestimated [16] as the national death register could not be accessed.

In the era of 'test-and-treat' the CD4 result is only reviewed after ART has started. This means that the vulnerable, low CD4 patients may be put at risk if they have TB or cryptococcal infection that may preferentially require treatment initiation before starting ART. POC testing for Cryptococcal Ag, TB (TBLAM and Xpert®MTB/ RIF), Haemoglobin, Creatinine, Hepatitis B and HIV viral load are all commercially available [62]. Cotrimoxazole prophylaxis, for Pneumocystis pneumonia prevention, is also only initiated after ART start, and is commonly missed in as many $70 \%$ of patients [4]. This causes additional risk to the vulnerable patients and could be contributing to the plateauing of the HIV death rate in South Africa since 2012. Patients who default ART may return with low CD4 counts. In 2016 in the Western Cape, 52\% of patients with CD4<50cells $/ \mathrm{mm}^{3}$ had prior ART exposure [6]. They may not disclose their prior treatment and with the additional risk of drug resistance, they are at higher risk of dying [63]. Immunodeficiency associated with low CD4 counts also fuels the high TB incidence which compounds mortality in this vulnerable population [64].

In 2020, the WHO released guidance on the use of POC CD4 tests for advanced HIV disease with their product profile preferring a device-free test [65]. The benefit of a POC device that is connected is that data can be stored and reviewed centrally for reporting, monitoring and quality purposes and retrieved by health care workers at different clinics should patients move. This is in keeping with advancing mobile health or mHealth that is growing globally [66]. The PIMA ${ }^{\mathrm{TM}} \mathrm{CD} 4$ devices are robust, tried and tested in the field, having WHO prequalification since 2012 and used widely in lower- and middle-income settings. With CD4 being linked to advanced HIV disease and thus mortality, it is important to monitor CD4s across maturing ART programmes to monitor these vulnerable patients. Next generation POC devices will perform multiple assays and combinations of assays within 10 minutes, which would further assist the clinical team in making on the spot decisions across the broad spectrum of communicable and non-communicable diseases for best patient care. Connectivity allows disease surveillance, quality monitoring and supply chain monitoring. South Africa has not implemented POC CD4 testing due to sufficient central laboratory capacity, but this deserves a clinical review.

\section{CONCLUSIONS}

Where POC CD4 testing was previously found to improve assessment of ART eligibility and hasten ART start, it should now be used to improve rapid assessment of advanced HIV disease in those initiating ART, returning from interrupted ART and failing ART. This should include POC TBLAM testing $\left(C D 4<100-200 \mathrm{cell} / \mathrm{s} / \mathrm{mm}^{3}\right)$, 
Cryptococcal Ag testing $\left(C D 4<100\right.$ cells $\left./ \mathrm{mm}^{3}\right)$, and the differentiated care package required for these patients to improve care and decrease morbidity and mortality which will reduce the cost and health care burden of hospitalization. It is time to contend for those with low CD4 counts who are most likely to die of AIDS.

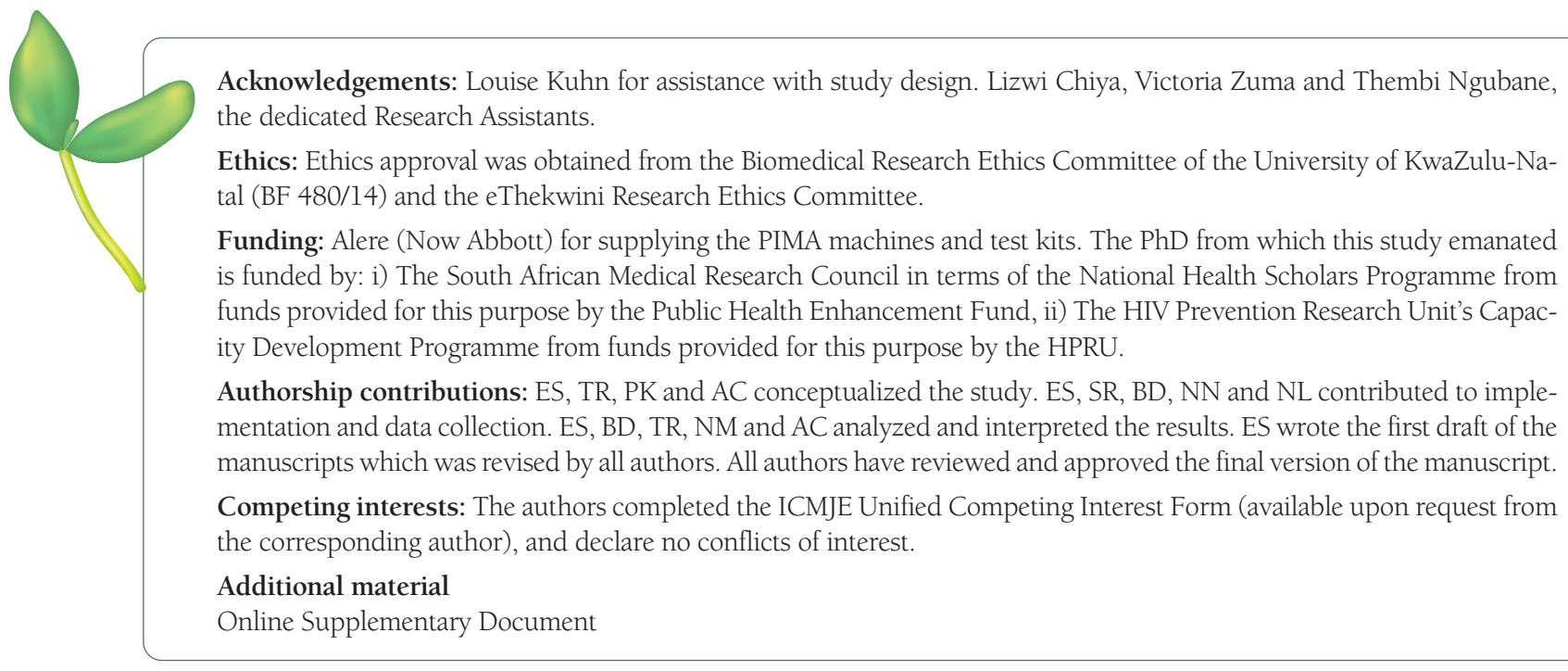

1 UNAIDS. UNAIDS DATA 2020. Available: https://wwwunaidsorg/sites/default/files/media_asset/2020_aids-data-book_enpdf. Accessed 30 December 2020

2 UNAIDS. Fact Sheet: South Africa. 2020. Available: https://wwwunaidsorg/en/regionscountries/countries/southafrica. Accessed 6 November 2021.

3 Reniers G, Blom S, Calvert C, Martin-Onraet A, Herbst AJ, Eaton JW, et al. Trends in the burden of HIV mortality after roll-out of antiretroviral therapy in KwaZulu-Natal, South Africa: an observational community cohort study. Lancet HIV. 2017;4:e11321. Medline:27956187 doi:10.1016/S2352-3018(16)30225-9

4 Lilian RR, Rees K, Mabitsi M, McIntyre JA, Struthers HE, Peters RP. Baseline CD4 and mortality trends in the South African human immunodeficiency virus programme: Analysis of routine data. South Afr J HIV Med. 2019;20:963. Medline:31392037 doi:10.4102/sajhivmed.v20il.963

5 Osler M, Hilderbrand K, Goemaere E, Ford N, Smith M, Meintjes G, et al. The continuing burden of advanced HIV disease over 10 years of increasing antiretroviral therapy coverage in South Africa. Clin Infect Dis. 2018;66 suppl_2:S118-25. Medline:29514233 doi:10.1093/cid/cix1140

6 Carmona S, Bor J, Nattey C, Maughan-Brown B, Maskew M, Fox MP, et al. Persistent High Burden of Advanced HIV Disease Among Patients Seeking Care in South Africa's National HIV Program: Data From a Nationwide Laboratory Cohort. Clin Infect Dis. 2018;66 suppl_2:S111-7. Medline:29514238 doi:10.1093/cid/ciy045

7 Lamp K, McGovern S, Fong Y, Atem CD, Nfetam JBE, Nzuobontane D, et al. Proportions of CD4 test results indicating advanced HIV disease remain consistently high at primary health care facilities across four high HIV burden countries. PLoS One. 2020;15:e0226987. Medline:31910221 doi:10.1371/journal.pone.0226987

8 Kaplan SR, Oosthuizen C, Stinson K, Little F, Euvrard J, Schomaker M, et al. Contemporary disengagement from antiretroviral therapy in Khayelitsha, South Africa: A cohort study. PLoS Med. 2017;14:e1002407. Medline:29112692 doi:10.1371/ journal.pmed.1002407

9 Ousley J, Niyibizi AA, Wanjala S, Vandenbulcke A, Kirubi B, Omwoyo W, et al. High proportions of patients with advanced HIV are antiretroviral therapy experienced: hospitalization outcomes from 2 sub-Saharan African sites. Clin Infect Dis. 2018;66 suppl_2:S126-31. Medline:29514239 doi:10.1093/cid/ciy103

10 Meyer-Rath G, Brennan AT, Fox MP, Modisenyane T, Tshabangu N, Mohapi L, et al. Rates and cost of hospitalisation before and after initiation of antiretroviral therapy in urban and rural settings in South Africa. J Acquir Immune Defic Syndr. 2013;62:3228. Medline:23187948 doi:10.1097/QAI.0b013e31827e8785

11 Teasdale CA, Yuengling K, Preko P, Syowai M, Ndagije F, Rabkin M, et al. Persons living with HIV with advanced HIV disease: need for novel care models. J Int AIDS Soc. 2018;21:e25210. Medline:30549245 doi:10.1002/jia2.25210

12 Ford N, Shubber Z, Meintjes G, Grinsztejn B, Eholie S, Mills EJ, et al. Causes of hospital admission among people living with HIV worldwide: a systematic review and meta-analysis. Lancet HIV. 2015;2:e438-44. Medline:26423651 doi:10.1016/S23523018(15)00137-X

13 Gupta-Wright A, Fielding K, van Oosterhout JJ, Alufandika M, Grint DJ, Chimbayo E, et al. Virological failure, HIV-1 drug resistance, and early mortality in adults admitted to hospital in Malawi: an observational cohort study. Lancet HIV. 2020;7:e6208. Medline:32890497 doi:10.1016/S2352-3018(20)30172-7 
14 Gupta RK, Gregson J, Parkin N, Haile-Selassie H, Tanuri A, Forero LA, et al. HIV-1 drug resistance before initiation or re-initiation of first-line antiretroviral therapy in low-income and middle-income countries: a systematic review and meta-regression analysis. Lancet Infect Dis. 2018;18:346-55. Medline:29198909 doi:10.1016/S1473-3099(17)30702-8

15 Collaborations TIaCC. Global Trends in CD4 Cell Count at the Start of Antiretroviral Therapy: Collaborative Study of Treatment Programs. Clin Infect Dis. 2018;66:893-903. Medline:29373672 doi:10.1093/cid/cix915

16 Geng EH, Odeny TA, Lyamuya RE, Nakiwogga-Muwanga A, Diero L, Bwana M, et al. Estimation of mortality among HIV-infected people on antiretroviral treatment in east Africa: a sampling based approach in an observational, multisite, cohort study. Lancet HIV. 2015;2:e107-16. Medline:26424542 doi:10.1016/S2352-3018(15)00002-8

17 Brault MA, Spiegelman D, Hargreaves J, Nash D, Vermund SH. Treatment as prevention: concepts and challenges for reducing HIV incidence. J Acquir Immune Defic Syndr. 2019;82:S104-12. Medline:31658196 doi:10.1097/QAI.0000000000002168

18 Larmarange J, Diallo MH, McGrath N, Iwuji C, Plazy M, Thiébaut R, et al. The impact of population dynamics on the population HIV care cascade: results from the ANRS 12249 Treatment as Prevention trial in rural KwaZulu-Natal (South Africa). J Int AIDS Soc. 2018;21:e25128. Medline:30027600 doi:10.1002/jia2.25128

19 World Health Organization. Guideline on when to start antiretroviral therapy and on pre-exposure prophylaxis for HIV. Geneva, Switzerland: WHO; 2015

20 World Health Organization. Guidelines for managing advanced HIV disease and rapid initiation of antiretroviral therapy. Geneva: WHO; 2017.

21 Onoya D, Sineke T, Hendrickson C, Mokhele I, Maskew M, Long LC, et al. Impact of the test and treat policy on delays in antiretroviral therapy initiation among adult HIV positive patients from six clinics in Johannesburg, South Africa: results from a prospective cohort study. BMJ Open. 2020;10:e030228. Medline:32213514 doi:10.1136/bmjopen-2019-030228

22 Zaniewski E, Ostinelli CHD, Chammartin F, Maxwell N, Davies M-A, Euvrard J, et al. Trends in CD4 and viral load testing 2005 to 2018: Multi-cohort study of people living with HIV in Southern Africa. J Int AIDS Soc. 2020;23:e25546. Medline:32640106 doi:10.1002/jia2.25546

23 Leeme TB, Mine M, Lechiile K, Mulenga F, Mosepele M, Mphoyakgosi T, et al. Utility of CD4 count measurement in the era of universal antiretroviral therapy: an analysis of routine laboratory data in Botswana. HIV Med. 2021;22:1-10. Medline:32876378 doi:10.1111/hiv.12951

24 Peeling RW, Ford N. Reprising the role of CD4 cell count in HIV programmes. Lancet HIV. 2017;4(9):e377-e378. Medline:28579226 doi:10.1016/S2352-3018(17)30096-6

25 Ehrenkranz PD, Baptiste SL, Bygrave H, Ellman T, Doi N, Grimsrud A, et al. The missed potential of CD4 and viral load testing to improve clinical outcomes for people living with HIV in lower-resource settings. PLoS Med. 2019;16:e1002820. Medline:31141516 doi:10.1371/journal.pmed.1002820

26 Scott LE, Campbell J, Westerman L, Kestens L, Vojnov L, Kohastsu L, et al. A meta-analysis of the performance of the Pima TM CD4 for point of care testing. BMC Med. 2015;13:1. doi:10.1186/s12916-015-0396-2

27 Skhosana M, Reddy S, Reddy T, Ntoyanto S, Spooner E, Ramjee G, et al. PIMA point-of-care testing for CD4 counts in predicting antiretroviral initiation in HIV-infected individuals in KwaZulu-Natal, Durban, South Africa. South Afr J HIV Med. 2016;17:144. Medline:29568605 doi:10.4102/sajhivmed.v17il.444

28 Heffernan A, Barber E, Thomas R, Fraser C, Pickles M, Cori A. Impact and Cost-Effectiveness of Point-Of-Care CD4 Testing on the HIV Epidemic in South Africa. PLoS One. 2016;11:e0158303. Medline:27391129 doi:10.1371/journal.pone.0158303

29 Simeon K, Sharma M, Dorward J, Naidoo J, Dlamini N, Moodley P, et al. Comparative cost analysis of point-of-care versus laboratory-based testing to initiate and monitor HIV treatment in South Africa. PLoS One. 2019;14:e0223669. Medline:31618220 doi:10.1371/journal.pone.0223669

30 Wynberg E, Cooke G, Shroufi A, Reid SD, Ford N. Impact of point-of-care CD4 testing on linkage to HIV care: a systematic review. J Int AIDS Soc. 2014;17:18809. Medline:24447595 doi:10.7448/IAS.17.1.18809

31 Vojnov L, Markby J, Boeke C, Harris L, Ford N, Peter T. POC CD4 Testing Improves Linkage to HIV Care and Timeliness of ART Initiation in a Public Health Approach: A Systematic Review and Meta-Analysis. PLoS One. 2016;11:e0155256. Medline:27175484 doi:10.1371/journal.pone.0155256

32 Elul B, Lamb MR, Lahuerta M, Abacassamo F, Ahoua L, Kujawski SA, et al. A combination intervention strategy to improve linkage to and retention in HIV care following diagnosis in Mozambique: A cluster-randomized study. PLoS Med. 2017;14:e1002433. Medline:29136001 doi:10.1371/journal.pmed.1002433

33 Rosen S, Maskew M, Fox MP, Nyoni C, Mongwenyana C, Malete G, et al. Initiating Antiretroviral Therapy for HIV at a Patient's First Clinic Visit: The RapIT Randomized Controlled Trial. PLoS Med. 2016;13:e1002015. Medline:27163694 doi:10.1371/ journal.pmed.1002015

34 Barnabas RV, van Rooyen H, Tumwesigye E, Murnane PM, Baeten JM, Humphries H, et al. Initiation of antiretroviral therapy and viral suppression after home HIV testing and counselling in KwaZulu-Natal, South Africa, and Mbarara district, Uganda: a prospective, observational intervention study. Lancet HIV. 2014;1:e68-76. Medline:25601912 doi:10.1016/S23523018(14)70024-4

35 Reddy S, Gibbs A, Spooner E, Ngomane N, Reddy T, Luthuli N, et al. Assessment of the Impact of Rapid Point-of-Care CD4 Testing in Primary Healthcare Clinic Settings: A Survey Study of Client and Provider Perspectives. Diagnostics (Basel). 2020;10:81. Medline:32024166 doi:10.3390/diagnostics10020081

36 Mashamba-Thompson TP, Sartorius B, Drain PK. Operational assessment of point-of-care diagnostics in rural primary healthcare clinics of KwaZulu-Natal, South Africa: a cross-sectional survey. BMC Health Serv Res. 2018;18:380. Medline:29843711 doi:10.1186/s12913-018-3207-6 
37 Kharsany AB, Cawood C, Khanyile D, Lewis L, Grobler A, Puren A, et al. Community-based HIV prevalence in KwaZulu-Natal, South Africa: results of a cross-sectional household survey. Lancet HIV. 2018;5:e427-37. Medline:30021700 doi:10.1016/ S2352-3018(18)30104-8

38 Fomundam HN, Tesfay A, Mushipe S, Mosina M, Boshielo C, Nyambi H, et al. Prevalence and predictors of late presentation for HIV care in South Africa. SAMJ: S Afr Med J. 2017;107:1058-64. Medline:29262956 doi:10.7196/SAMJ.2017.v107i12.12358

39 Mberi MN, Kuonza LR, Dube NM, Nattey C, Manda S, Summers R. Determinants of loss to follow-up in patients on antiretroviral treatment, South Africa, 2004-2012: a cohort study. BMC Health Serv Res. 2015;15:259. Medline:26141729 doi:10.1186/ s12913-015-0912-2

40 Camlin CS, Cassels S, Seeley J. Bringing population mobility into focus to achieve HIV prevention goals. J Int AIDS Soc. 2018;21:e25136. Medline:30027588 doi:10.1002/jia2.25136

41 Clouse K, Vermund SH, Maskew M, Lurie MN, MacLeod W, Malete G, et al. Mobility and Clinic Switching Among Postpartum Women Considered Lost to HIV Care in South Africa. J Acquir Immune Defic Syndr. 2017;74:383-9. Medline:28225717 doi:10.1097/QAI.0000000000001284

42 Jani IV, Sitoe NE, Alfai ER, Chongo PL, Quevedo JI, Rocha BM, et al. Effect of point-of-care CD4 cell count tests on retention of patients and rates of antiretroviral therapy initiation in primary health clinics: an observational cohort study. Lancet. 2011;378:1572-9. Medline:21951656 doi:10.1016/S0140-6736(11)61052-0

43 Page-Shipp L, Lewis JJ, Velen K, Senoge S, Zishiri E, Popane F, et al. Household point of care CD4 testing and isoniazid preventive therapy initiation in a household TB contact tracing programme in two districts of South Africa. PLoS One. 2018;13:e0192089. Medline:29499060 doi:10.1371/journal.pone.0192089

44 Stevens WS, Gous NM, MacLeod WB, Long LC, Variava E, Martinson NA, et al. Multidisciplinary point-of-care testing in South African primary health care clinics accelerates HIV ART initiation but does not alter retention in care. J Acquir Immune Defic Syndr. 2017;76:65-73. Medline:28542080 doi:10.1097/QAI.0000000000001456

45 Joseph J, Gotora T, Erlwanger AS, Mushavi A, Zizhou S, Masuka N, et al. Impact of point-of-care CD4 testing on retention in care among HIV-positive pregnant and breastfeeding women in the context of Option B+ in Zimbabwe: a cluster randomized controlled trial. J Acquir Immune Defic Syndr. 2017;75:S190-7. Medline:28498189 doi:10.1097/QAI.0000000000001341

46 Hoffmann CJ, Mabuto T, Ginindza S, Fielding KL, Kubeka G, Dowdy DW, et al. Strategies to accelerate HIV care and antiretroviral therapy initiation after HIV diagnosis: a randomized trial. J Acquir Immune Defic Syndr. 2017;75:540-7. Medline:28471840 doi:10.1097/QAI.0000000000001428

47 Amanyire G, Semitala FC, Namusobya J, Katuramu R, Kampiire L, Wallenta J, et al. Effects of a multicomponent intervention to streamline initiation of antiretroviral therapy in Africa: a stepped-wedge cluster-randomised trial. Lancet HIV. 2016;3:e53948. Medline:27658873 doi:10.1016/S2352-3018(16)30090-X

48 Lambdin BH, Cheng B, Peter T, Mbwambo J, Apollo T, Dunbar M, et al. Implementing implementation science: an approach for HIV prevention, care and treatment programs. Curr HIV Res. 2015;13:244-9. Medline:25986374 doi:10.2174/157016 2X1303150506185423

49 Ortblad KF, Baeten JM, Cherutich P, Wamicwe JN, Wasserheit JN. The arc of HIV epidemics in sub-Saharan Africa: new challenges with concentrating epidemics in the era of 90-90-90. Curr Opin HIV AIDS. 2019;14:354-65. Medline:31343457 doi:10.1097/COH.0000000000000569

50 Haas AD, Zaniewski E, Anderegg N, Ford N, Fox MP, Vinikoor M, et al. Retention and mortality on antiretroviral therapy in sub-Saharan Africa: collaborative analyses of HIV treatment programmes. J Int AIDS Soc. 2018;21:e25084. Medline:29479867 doi:10.1002/jia2.25084

51 Fox MP, Bor J, Brennan AT, MacLeod WB, Maskew M, Stevens WS, et al. Estimating retention in HIV care accounting for patient transfers: A national laboratory cohort study in South Africa. PLoS Med. 2018;15:e1002589. Medline:29889844 doi:10.1371/ journal.pmed.1002589

52 UNAIDS. 90-90-90: an ambitious treatment target to help end the AIDS epidemic. UNAIDS Geneva, Switzerland; 2014.

53 Takuva S, Brown AE, Pillay Y, Delpech V, Puren AJ. The continuum of HIV care in South Africa: implications for achieving the second and third UNAIDS 90-90-90 targets. AIDS. 2017;31:545-52. Medline:28121668 doi:10.1097/QAD.0000000000001340

54 Hakim J, Musiime V, Szubert AJ, Mallewa J, Siika A, Agutu C, et al. Enhanced prophylaxis plus antiretroviral therapy for advanced HIV infection in Africa. N Engl J Med. 2017;377:233-45. Medline:28723333 doi:10.1056/NEJMoal615822

55 Gabillard D, Lewden C, Ndoye I, Moh R, Segeral O, Tonwe-Gold B, et al. Mortality, AIDS-morbidity, and loss to follow-up by current CD4 cell count among HIV-1-infected adults receiving antiretroviral therapy in Africa and Asia: data from the ANRS 12222 collaboration. J Acquir Immune Defic Syndr. 2013;62:555-61. Medline:23274931 doi:10.1097/QAI.0b013e3182821821

56 Wahls TL, Cram PM. The frequency of missed test results and associated treatment delays in a highly computerized health system. BMC Fam Pract. 2007;8:32. Medline:17519017 doi:10.1186/1471-2296-8-32

57 Dandachi D, May SB, Davila JA, Cully J, Amico KR, Kallen MA, et al. The association of unmet needs with subsequent retention in care and HIV suppression among hospitalized patients with HIV who are out of care. J Acquir Immune Defic Syndr. 2019;80:64-72. Medline:30272637 doi:10.1097/QAI.0000000000001874

58 Dorward J, Mabuto T, Charalambous S, Fielding KL, Hoffmann CJ. Factors associated with poor linkage to HIV care in South Africa: secondary analysis of data from the Thol'impilo trial. J Acquir Immune Defic Syndr. 2017;76:453-60. Medline:28961678 doi:10.1097/QAI.0000000000001550

59 Eshun-Wilson I, Rohwer A, Hendricks L, Oliver S, Garner P. Being HIV positive and staying on antiretroviral therapy in Africa: A qualitative systematic review and theoretical model. PLoS One. 2019;14:e0210408. Medline:30629648 doi:10.1371/ journal.pone. 0210408 
60 Geng EH, Odeny TA, Lyamuya R, Nakiwogga-Muwanga A, Diero L, Bwana M, et al. Retention in Care and Patient-Reported Reasons for Undocumented Transfer or Stopping Care Among HIV-Infected Patients on Antiretroviral Therapy in Eastern Africa: Application of a Sampling-Based Approach. Clin Infect Dis. 2016;62:935-44. Medline:26679625 doi:10.1093/cid/civ1004

61 Kaindjee-Tjituka F, Sawadogo S, Mutandi G, Maher AD, Salomo N, Mbapaha C, et al. Task-shifting point-of-care CD4+ testing to lay health workers in HIV care and treatment services in Namibia. Afr J Lab Med. 2017;6:643. Medline:29159139 doi:10.4102/ajlm.v6il.643

62 Gous NM, Scott LE, Potgieter J, Ntabeni L, Sanne I, Stevens WS. Implementation and Operational Research: Implementation of Multiple Point-of-Care Testing in 2 HIV Antiretroviral Treatment Clinics in South Africa. J Acquir Immune Defic Syndr. 2016;71:e34-43. Medline:26484742 doi:10.1097/QAI.0000000000000872

63 Gregson J, Kaleebu P, Marconi VC, van Vuuren C, Ndembi N, Hamers RL, et al. Occult HIV-1 drug resistance to thymidine analogues following failure of first-line tenofovir combined with a cytosine analogue and nevirapine or efavirenz in sub Saharan Africa: a retrospective multi-centre cohort study. Lancet Infect Dis. 2017;17:296-304. Medline:27914856 doi:10.1016/ S1473-3099(16)30469-8

64 Lawn SD, Myer L, Edwards D, Bekker L-G, Wood R. Short-term and long-term risk of tuberculosis associated with CD4 cell recovery during antiretroviral therapy in South Africa. AIDS. 2009;23:1717-25. Medline:19461502 doi:10.1097/ QAD.0b013e32832d3b6d

65 World Health Organization. Point-of-care CD4 tests to support the identification of individuals with advanced HIV disease, 03 April 2020. Geneva: World Health Organization; 2020.

66 Wood CS, Thomas MR, Budd J, Mashamba-Thompson TP, Herbst K, Pillay D, et al. Taking connected mobile-health diagnostics of infectious diseases to the field. Nature. 2019;566:467-74. Medline:30814711 doi:10.1038/s41586-019-0956-2 